\title{
PERBANDINGAN NILAI KEKERASAN DAN STRUKTUR MIKRO MATERIAL PISTON SEPEDA MOTOR 4 TAK ORIGINAL DAN IMITASI
}

\author{
Media Nofri ${ }^{1}$ \\ Program Studi Teknik Mesin, Universitas Tama Jagakarsa, Jakarta ${ }^{1}$ \\ email $^{1}$ : medi.bagindo@gmail.com
}

\begin{abstract}
The function of the piston is to accept the pressure from the combustion of the gas mixture and continue the pressure to pass through the connecting rod. The use of aluminum as a piston material is inseparable from its properties and is very suitable for pistons. $n$ this study three piston materials were tested, namely piston A (Original), B (Imitation 1) and C (Imitation 2) with Aluminum material which also contained Silicon (AlSi). The tests carried out included testing the chemical composition, microstructure photographed from various position and hardness by the Vickers method. The results of these tests obtained varying hardness values with an average piston A value of $129 \mathrm{HV}$, piston B an average of 148.2 $\mathrm{HV}$, piston $C$ an average of $135.2 \mathrm{HV}$. The results of the microstructure test on piston $C$ have srinkage casting defects and porosity defects while piston A and B have no defects. Whereas in testing the chemical composition of the value contained in the piston piston $A$ has $\mathrm{Al} 81.7 \%$ and Si $14.0 \%$, piston B Al $82.2 \%$ and Si $14.3 \%$, piston $C$ Al $83.5 \%$ and The $13.2 \%$. From the results of the chemical composition test, the hardness value and microstructure of the three materials can be said to have almost the same value
\end{abstract}

Keywords: Piston, chemical composition, microstructure, hardness.

\section{PENDAHULUAN}

Di era modern saat ini kebutuhan akan alat transportasi sangat berperan baik alat transportasi umum dan pribadi. Dalam pemenuhan kebutuhan alat tranportasi tidak lepas dari kemajuan industri otomotif. Sebagai contoh mobil, motor, bus, truk dll. Kecanggihan alat transportasi sangat berhubungan erat dengan kepresisian komponen mesin. Piston adalah sumbat geser yang terpasang di dalam sebuah silinder mesin pembakaran dalam silinder hidrolik, peneumatik dan silinder pompa. Piston merupakan salah satu komponenen penting didalam sebuah silnder pembakaran, maka kepresisian dimensi piston berpengaruh dalam proses pembakaran. Dari hasil pembakaran didalam silinder mesin maka diperoleh hasil pembakaran untuk menggerakan mesin. Oleh karena itu kualitas dimensi merupakan unsur utama yang harus diperhatikan ntuk mendapatkan hasil yang baik dibutuhkan material dengan komposisi yang seimbang antara lain besi, alumunium, magnesium, dll serta proses produksi yang mendukung.

Fungsi piston adalah sebagai alat untuk menghisap bahan bakar, memampatkan bahan bakar (kompresi), menampung tenaga dan ekspansi gas yang bertekanan tinggi dengan temperatur tinggi pula. Piston bekerja di dalam lubang silinder dengan gerakan linear dan dihubungkan dengan poros engkol melalui batang piston (connecting rod). Piston bila kena panas akan mengembang, pengembangan piston ini condong untuk berbentuk oval ke arah dimana pena piston dimasukkan. Selain itu piston dapat mengalami keausan akibat bergesekan dengan dinding lubang silinder.

Piston dibuat dari bahan aluminium karena piston harus ringan, kuat dan tahan temperatur tinggi. Oleh karena itu aluminium sebagai bahan baku komponen sering didapatkan dalam bentuk paduan dengan unsur seperti ; $\mathrm{Cu}, \mathrm{Zn}, \mathrm{Si}, \mathrm{Mg}$, Sn, dan sebagainya sehingga dapat meningkatkan kekuatan mekaniknya.

Berdasarkan hal tersebut di atas maka dilakukan penelitian analisa perbandingan dan faktor-faktor penentu kualitas material piston sepeda motor merk A, B dan C.

\section{TINJAUAN PUSTAKA}

\section{Pengertian Piston}

Piston adalah sumbat geser yang terpasang di dalam sebuah silinder mesin pembakaran dalam silinder hidraulik, pneumatik, dan silinder pompa. Piston adalah komponen yang bekerja extra berat, karena tugasnya menahan ledakan dalam ruang bakar. Selain harus tahan tekanan piston juga wajib tahan 
panas. Piston merupakan salah satu komponen sepeda motor yang berkerja pada tekanan dan temperatur tinggi. Piston harus memiliki daya tahan terhadap korosi dan abrasi yang tinggi, koefisien pemuaian yang rendah, mempunyai kekuatan/ kekerasan yang tinggi dan ringan.

Piston dibuat dari bahan aluminium karena piston harus ringan, kuat dan tahan temperatur tinggi. Paduan yang dipakai biasanya dengan komposisi eutektik yaitu yang kandungan silikonnya antara 1013\%. Piston berfungsi sebagai alat penampang untuk menahan tekanan pada saat langah kompresi dan langkah tenaga.

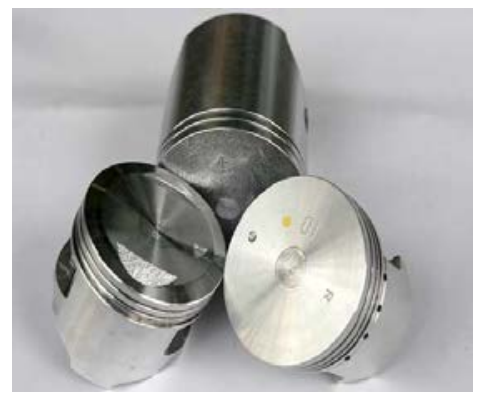

Gambar 1. Piston

\section{Spesifikasi Piston Merk a, b dan c.}

Untuk spesifikasi piston yang di gunakan ini adalah berbagai merk piston antara original dan imitasi. Piston motor ini berbahan aluminium paduan Al-Si karena memiliki sifat mampu cor yang baik dan tahan korosi, paduan aluminium di kelompokan dengan unsur-unsur paduan utama yang di kandungnya.

Piston untuk pengujian ini adalah piston untuk kendaraan bermotor dengan kapasitas 100 cc, yang mempunyai kinerja 4 kali langkah kerja dengan ukuran piston oversize 0 (nol) standard yang berdiameter $26 \mathrm{~mm}$.

\section{Prinsip Kerja Motor 4 Langkah.}

Motor bakar empat langkah adalah mesin pembakaran dalam yang dalam satu kali siklus pembakaran akan mengalami empat langkah kerja piston. Sekarang ini, mesin pembakaran dalam pada mobil, sepeda motor, truk, kapal, alat berat dan sebagainya, umumnya menggunakan siklus empat langkah.

Empat langkah tersebut meliputi langkah hisap (pemasukan), kompresi, tenaga dan langkah buang. Yang secara keseluruhan memerlukan dua putaran poros engkol (crankshaft) per satu siklus pada mesin bensin. Kemampuan mesin motor bakar untuk merubah energi bahan bakar yang masuk sehingga menghasilkan daya berguna disebut kemampuan mesin atau prestasi mesin.

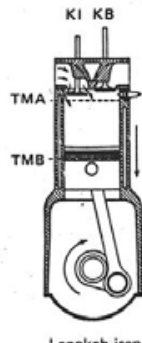

I angkah isop
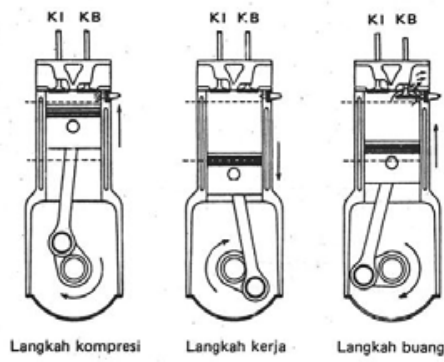

Gambar 2.
Prinsip Kerja Motor 4 (empat) Langkah

\section{Aluminium}

Aluminium merupakan logam ringan mempunyai ketahanan korosi yang baik dan hantaran listrik yang baik dan sifat-sifat baik lainnya sebagai sifat logam. Sebagai tambahan terhadap kekuatan mekaniknya yang sangat meningkat dengan penambahan $\mathrm{Cu}, \mathrm{Mg}$, Si, Mn, Zn, Ni dan sebagainya, secara satu persatu atau bersama-sama, memberikan juga sifat-sifat yang baik lainnya seperti ketahanan korosi, ketahanan aus, koefisien pemuaian rendah dan sebagainya.

Aluminium adalah logam yang ringan dengan berat jenis 2.7 gram/cm3 setelah Magnesium (1.7 gram/cm3) dan Berilium(1.85 gram/cm3) atau sekitar $1 / 3$ dari berat jenis besi maupun tembaga. Konduktifitas listriknya 60 \% lebih dari tembaga sehingga juga digunakan untuk peralatan listrik. Selain itu juga memiliki sifat penghantar panas, memiliki sifat pantul sinar yang baik sehingga digunakan pula pada komponen mesin, alat penukar panas, cermin pantul, komponen industri kimia dll.

Aluminium murni mempunyai kemurnian hingga 99,96\% dan minimal 99\%. zat pengotornya berupa unsur Fe dan Si. Aluminium paduan memiliki berbagai kandungan atom atau unsur utama (mayor) dan minor. Unsur mayor seperti Mg, Mn, Zn, Cu, dan Si sedangkan unsur minor seperti $\mathrm{Cr}, \mathrm{Ca}, \mathrm{Pb}, \mathrm{Ag}, \mathrm{Fe}$, Sn, Zr, Ti, Sn, dan lain-lain.

1. Silikon (Si).

Dengan atau tanpa paduan lainnya silikon mempunyai ketahanan terhadap korosi. Bila bersama aluminium ia akan mempunyai kekuatan yang tinggi setelah perlakuan panas, tetapi silicon mempunyai kualitas pengerjaan mesin yang jelek, selain itu juga mempunyai ketahanan koefisien panas yang rendah.

2. Tembaga $(\mathrm{Cu})$.

Dengan unsur tembaga pada aluminium akan meningkatkan kekerasannya dan kekuatannya karena tembaga bisa memperhalus struktur butir dan akan mempunyai kualitas pengerjaan mesin yang baik, mampu tempa, keuletan yang baik dan mudah dibentuk.

3. Magnesium (Mg) 
Unsur Magnesium pada aluminium akan mempunyai ketahanan korosi yang baik dan kualitas pengerjaan mesin yang baik, mampu las serta kekuatannya cukup.

4. Nikel (Ni)

Dengan unsur nikel aluminium dapat bekerja pada temperature tinggi, misalnya piston dan silinder head untuk motor.

5. Mangan (Mn)

Dengan unsur mangan aluminium sangat mudah dibentuk, tahan korosi baik, sifat dan mampu lasnya baik.

6. Seng (Zn).

Seng ditambahkan bersama-sama dengan unsur tembaga dalam prosentase kecil. Dengan penambahan ini akan meningkatkan sifat-sifat mekanik pada perlakuan panas, juga kemampuan mesin.

7. Ferrit (Fe).

Penambahan ferrit dimaksud untuk mengurangi penyusutan, tapi penambahan ferro $(\mathrm{Fe})$ yang besar akan menyebabkan struktur perubahan butir yang kasar, namun hal ini dapat diperbaiki dengan $\mathrm{Mg}$ atau Cr.

8. Titanium (Ti).

Penambahan titanium pada aluminium dimaksud untuk mendapat struktur butir yang halus. Biasanya penambahan bersama-sama dengan $\mathrm{Cr}$ dalam prosentase $0,1 \%$, titanium juga dapat meningkatkan mampu mesin.

Tabel 1. Karakteristik Aluminium

\begin{tabular}{|l|c|}
\hline \multicolumn{1}{|c|}{ Sifat-sifat } & $\begin{array}{c}\text { Aluminium } \\
\text { mumi tinggi }\end{array}$ \\
\hline Struktur kristal & FCC \\
\hline $\begin{array}{l}\text { Densitas pada } 20^{\circ} \mathrm{C} \text { (sat. } \\
103 \mathrm{~kg} / \mathrm{m} 3 \text { ) }\end{array}$ & 2.698 \\
\hline Titik cair $\left({ }^{\circ} \mathrm{C}\right)$ & 660.1 \\
\hline $\begin{array}{l}\text { Koefisien mulur panas } \\
\text { kawat } 20^{\circ} \sim 100^{\circ} \mathrm{C} \text { (10- } \\
6 / \mathrm{K})\end{array}$ & 23.9 \\
\hline $\begin{array}{l}\text { Konduktifitas panas } \\
20^{\circ} \sim 400^{\circ} \mathrm{C}\left(\mathrm{W} /\left(\mathrm{m} \_\mathrm{K}\right)\right.\end{array}$ & 238 \\
\hline $\begin{array}{l}\text { Tahanan listrik } 20^{\circ} \mathrm{C}(10- \\
8 \mathrm{KW} \text { m) }\end{array}$ & 2.69 \\
\hline Modulus elastisitas (GPa) & 70.5 \\
\hline Moduluskekakuan(GPa) & 26.0 \\
\hline
\end{tabular}

\section{Sifat Mekanik Aluminium}

Paduan aluminium di kelompokan dengan unsurunsur paduan utama yang di kandungnya, kelompok 4xxx adalah paduan dengan siliklon untuk kemudahan casting, silikon baik dalam paduan logam yang digunakan untuk casting. Silikon juga memiliki kepadatan rendah yang dapat memberikan keuntungan dalam mengurangi berat keseluruhan dari komponen cor. Silikon memiliki kelarutan yang sangat rendah dalam aluminium, karena itu endapan silikon sebagian hampir murni yang sulit dan karenanya meningkat ketahanan abrasi.

Paduan Al-Si memiliki sifat mampu cor yang baik, tahan korosi, serta dapat diproses dengan permesinan serta dapat di las. Diagram fasa Al-Si di tunjukan pada gambar dibawah, diagram ini digunakan sebagai pedoman umum untuk menganalisa perubahan fasa pada proses pengecoran pada proses Al-Si.

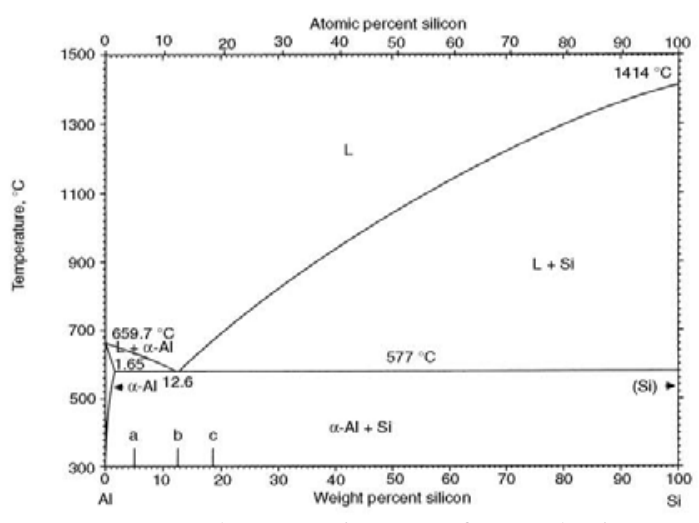

Gambar 3. Diagram fasa Al-Si

Dari diagram fasa terlihat bahwasannya temperatur cair dimulai dari $659,7^{\circ} \mathrm{C}$ sedangkan titik Si $1414{ }^{\circ} \mathrm{C}$. Bila dua komposisi ini dipadu maka paduan ini akan mendapat titik eutektik di $11 \% \mathrm{Al}$ dan $89 \%$ Si ditemperatur $577^{\circ} \mathrm{C}$, temperatur tersebut adalah temperatur akhir pada kristalisasi AlSi

\section{METODE PENELITIAN \\ Diagram Alir Proses Pengujian}

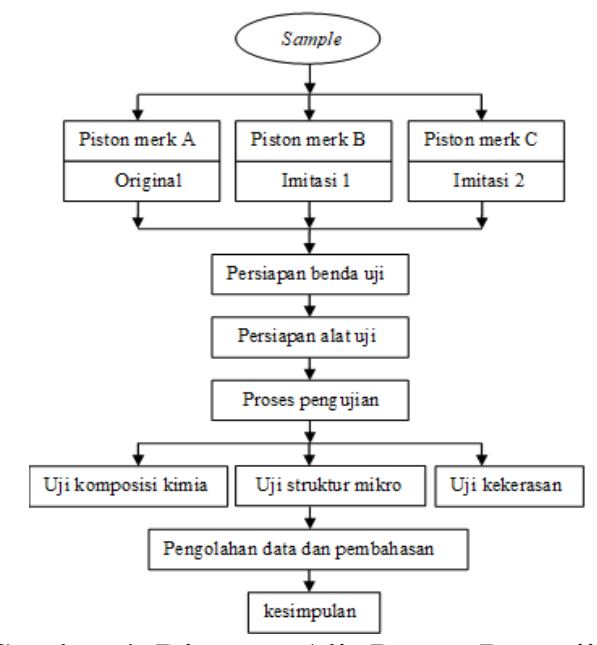

Gambar 4. Diagram Alir Proses Pengujian 


\section{Benda Uji Piston Merk A, B dan C.}

Material yang digunakan untuk proses pengujian terdiri dari 3 macam, yaitu piston merk A (original), B (imitasi 1) dan C (imitasi 2) yang digunakan pada kendaraan roda dua dengan kapasitas silinder 110 cc. Seperti contoh pada gambar pemotongan piston A berikut:

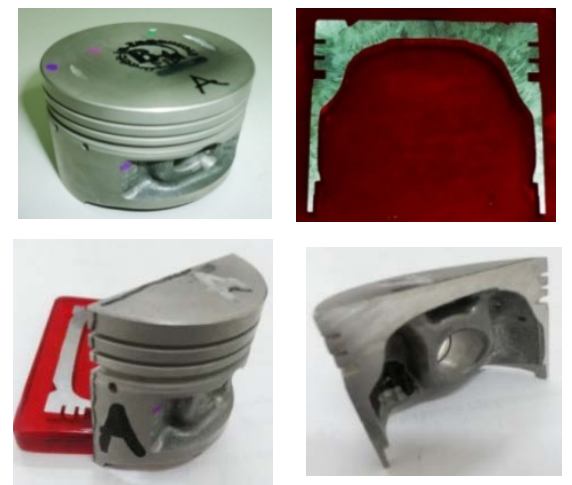

Gambar 5. Reparasi benda uji piston A

\section{Hasil Pengujian Piston Merk A, B dan C. \\ 1. Uji Komposisi Kimia}

Pengujian komposisi kimia bertujuan untuk mengetahui unsur-unsur kimia yang terkandung pada bahan atau komponen. Pengujian komposisi kimia bahan dilakukan dengan metode Optical Emission Spectrometer ( OES ) yang dilengkapi dengan sistim komputerisasi. Alat uji komposisi kimia dapat di lihat pada gambar:

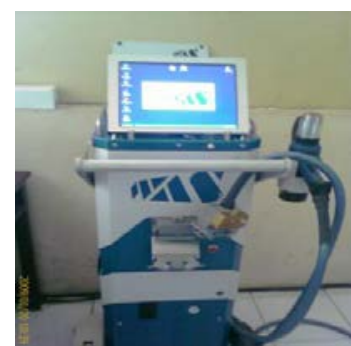

Gambar 6. Alat uji komposisi kimia

Persiapan benda uji

Adapun persiapan benda uji yang dilakukan sebagai berikut :

a) Penghalusan permukaan

Untuk benda uji komposisi kimia diusahakan memiliki permukaan yang halus. Alat yang digunakan dalam proses penghalusan ini adalah amplas dengan nomor 400, 600, 800 dan 1000 secara berurutan.

b) Pemolesan

Pemolesan benda uji dilakukan dengan menggunakan autosol dan kain halus untuk menghilangkan sisa-sisa goresan dan debu dari hasil pengamplasan agar di dapat permukaan.

\section{Prosedur pengujian}

Pada pengujian komposisi kimia ini, bahan atau komponen dapat langsung segera dianalisa oleh alat Optical Emission Spectrometer (OES) setelah dilakukan penghalusan permukaan dengan cara diamplas dan dipoles.

\section{Hasil pengujian komposisi kimia}

Setelah melakukan uji komposisi kimia pada piston merk A, B dan C maka hasilnya dapat di lihat pada tabel 3.1.

Tabel 2. Hasil Pengujian Komposisi Kimia Piston

\begin{tabular}{|c|c|c|c|c|}
\hline \multirow{2}{*}{ No. } & \multirow{2}{*}{ Unsur } & \multicolumn{3}{|c|}{ Kandungan unsur (\% berat) } \\
\cline { 3 - 5 } & & $\begin{array}{c}\text { Piston A } \\
\text { Original }\end{array}$ & $\begin{array}{c}\text { Piston B } \\
\text { Imitasi 1 }\end{array}$ & $\begin{array}{c}\text { Piston C } \\
\text { Imitasi 2 }\end{array}$ \\
\hline 1 & $\mathrm{Al}$ & 81.7 & 82.2 & 83.5 \\
\hline 2 & $\mathrm{Si}$ & 14.0 & 14.3 & 13.2 \\
\hline 3 & $\mathrm{Fe}$ & 0.567 & 0.197 & 0.544 \\
\hline 4 & $\mathrm{Mn}$ & 0.0317 & 0.852 & 0.122 \\
\hline 5 & $\mathrm{Cr}$ & 0.0182 & $<0.0010$ & 0.0355 \\
\hline 6 & $\mathrm{Ni}$ & 1.22 & 0.0000 & 0.00005 \\
\hline 7 & $\mathrm{Mg}$ & 0.946 & 1.22 & 0.892 \\
\hline 8 & $\mathrm{Cu}$ & 1.12 & 1.14 & 1.55 \\
\hline 9 & $\mathrm{Zn}$ & $<0.0050$ & $<0.0050$ & 0.0472 \\
\hline 10 & $\mathrm{~V}$ & 0.0043 & 0.0112 & 0.0079 \\
\hline 11 & $\mathrm{Be}$ & $<0.0010$ & $<0.0010$ & $<0.0010$ \\
\hline 12 & $\mathrm{Ti}$ & 0.0207 & $<0.0010$ & 0.0694 \\
\hline 13 & $\mathrm{Co}$ & $<0.0020$ & $<0.0020$ & $<0.0020$ \\
\hline 14 & $\mathrm{~Pb}$ & $<0.0250$ & $<0.0250$ & $<0.0250$ \\
\hline & & & & \\
\hline & & & & \\
\hline
\end{tabular}

Terlihat pada tabel diatas, hasil dari pengujian komposisi kimia pada piston yaitu kandungan yang didapat pada piston A, B dan C ini adalah kandungan AlSi ( Aluminium dan Silikon ), karena kandungan yang tertinggi diantara unsur kimia yang lainnya yaitu kandungan AlSi.

\section{Uji Struktur Mikro}

Pada pengujian ini bertujuan untuk mengetahui struktur mikro suatu logam, yang meliputi bentuk besar butiran dan arah struktur. Alat yang mendukung didalam pengujian struktur mikro terdiri dari :

a) Mesin grinding

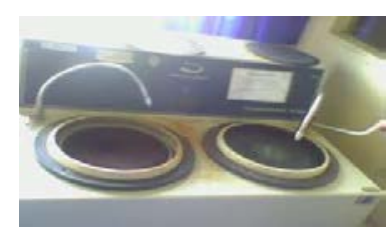

Gambar 7. Mesin grinding 
Mesin grinding berfungsi untuk menghaluskan dan menghilangkan partikel-partikel abrasive yang menempel pada benda uji.

b) Mesin poles

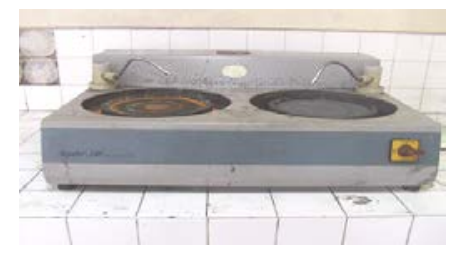

Gambar 8. Mesin poles

Proses polishing dilakukan dengan tujuan untuk menghilangkan goresan-goresan, inklusi non logam, retakan dan lain-lain yang terdapat pada benda uji.

c) Mikroskop optik

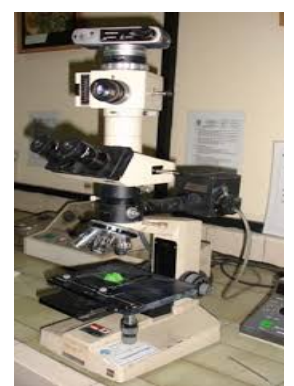

Gambar 9. Mikroskop optik

Setelah benda uji mengalami proses polishing, maka dilakukan pengetsaan dan selanjutnya diamati oleh mikroskop optik pada perbesaran yang berbeda-beda. Pengamatan oleh mikroskop optik ini bertujuan untuk mengetahui perbedaan struktur mikro dari masingmasing benda uji.

1. Persiapan benda uji

Adapun persiapan benda uji yang dilakukan dengan cara pemotongan suatu benda uji dengan sangat berhati-hati agar tidak terjadi panas yang berlebihan sehingga tidak terjadi perubahan struktur pada suatu benda uji tersebut.

2. Prosedur pengujian

Pengujian struktur mikro dilakukan dengan langkah-langkah sebagai berikut

a) Pengamatan atau analisa pendahuluan

- Siapkan benda uji dan lakukan pengamplasan.

- Bila permukaan belum merata maka lakukan penggerindaan sebelum proses pemolesan dilakukan.

b) Memoles mekanik

Sampel yang baru saja dipotong atau sampel yang telah terkorosi memiliki permukaan yang kasar. Permukaan yang kasar ini harus diratakan agar pengamatan struktur mudah untuk dilakukan.

- Siapkanlah alat mesin poles dengan amplas bermacam-macam grit.

- Lakukan pengamplasan dengan grit terendah (kasar) dan seterusnya diganti dengan yang lebih tinggi (halus).
- Pemolesan dengan amplas ini bisa dinyatakan selesai bila permukaan tersebut terlihat mengkilap serta halus merata.

c) Memoles pasta (alumina polish)

Apabila permukaan sampel kasar atau bergelombang, maka pengamatan struktur mikro akan sulit untuk dilakukan karena cahaya yang datang dari mikroskop dipantulkan secara acak oleh permukaan sampel. Tahap pemolesan dimulai dengan pemolesan kasar terlebih dahulu kemudian dilanjutkan dengan pemolesan halus.

- Siapkan bludru pada mesin poles, lalu tuangkan sedikit pasta alumina polish pada bludru tersebut.

- Selama pemolesan, benda uji harus di gerakan secara konstan dan diputar-putar untuk mencegah adanya goresan.

- Gunakan pasta (alumina polish) mulai dari mikron yang kasar dan di lanjutkan ke mikron yang lebih halus. Setiap selesai pemolesan, bersihkan dengan air dan amati permukaan dan dinyatakan selesai bila permukaan benda uji mengkilap dan halus merata.

d) Pengamatan atau analisa dengan mikroskop metalurgi

- Bersihkan benda uji dengan menggunakan kapas yang di basahi alkohol, usahakan jangan tersentuh permukaannya dengan tangan.

- Keringkan permukaan benda uji dengan udara panas ( dryer ).

- Amati permukaan tersebut memakai mikroskop dengan pembesaran 50, 200 dan 500 kali pembesaran. Apakah permukaan sudah terlihat bersih tanpa ada cacat ataupun goresan. Jika masih ada cacat atau goresan maka lakukan pemolesan tahap ke 3, apabila tidak lanjutkan pengetsaan.

e) Meng-etsa

Etsa merupakan proses penyerangan atau pengikisan batas butir secara selektif dan terkendali dengan pencelupan ke dalam larutan pengetsa baik menggunakan listrik maupun tidak ke permukaan sampel sehingga detil struktur yang akan diamati akan terlihat dengan jelas dan tajam.

Untuk beberapa material, mikrostruktur baru muncul jika diberikan zat etsa. Sehingga perlu pengetahuan yang tepat untuk memilih zat etsa yang tepat.

- Gunakan etsa dix's keller reagent.

- Pilih paling sedikit 3 lokasi pada permukaan benda uji lakukan pengetsaan satu-persatu dengan variasi waktu di setiap lokasi yang berbeda.

- Selama pengetsaan harus cepat, tujuannya agar mempermudah pembersihan permukaan yang telah dietsa dengan air. 
- Bersihkan lagi permukaan benda uji dengan alkohol lalu keringkan dengan udara panas dan selanjutnya dilakukan pengetsaan pada lokasi yang lain dengan waktu yang berbeda.

- Bila pengetsaan telah selesai, keringkan dengan udara panas dan jangan sampai tersentuh oleh tangan.

f) Pengamatan dan pemotretan

- Amati permukaan benda uji yang telah dietsa dengan mikroskop pada pembesaran 50, 200 dan 500 kali.

Amati permukaan disetiap etsaan pada lokasi permukaan benda uji, pilihlah bentuk struktur paling baik dan jelas

\section{Hasil pengujian struktur mikro}

Hasil pengujian struktur mikro ditampilkan dalam foto metalografi. Benda yang diuji yaitu piston merk A (original), B (imitasi 1) dan C (imitasi 2) dengan pembesaran 500 kali.

\section{SAMPLE}

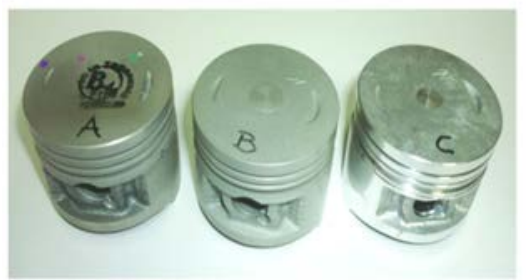

Gambar 10. Sampel piston untuk pengujian struktur mikro

Sampel metalografi setelah mengalami preparasi untuk pemeriksaan struktur mikro dan uji kekerasan, pengambilan sampel metalografi memotong/ membelah bidang gesek piston dengan linear sesuai dengan bekerjanya piston.

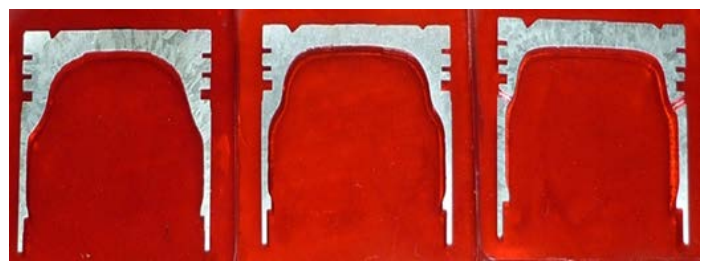

A (original) B (imitasi 1) C (imitasi 2) Gambar 11. Sampel Metalografi

\section{Piston A (Original)}
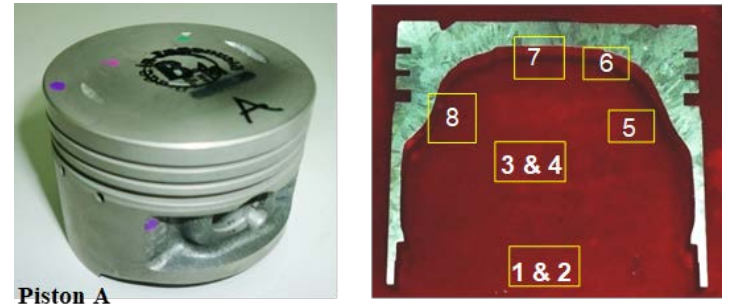

Gambar 12. Sample dan Lokasi pengambilan struktur mikro sampel A (Original).
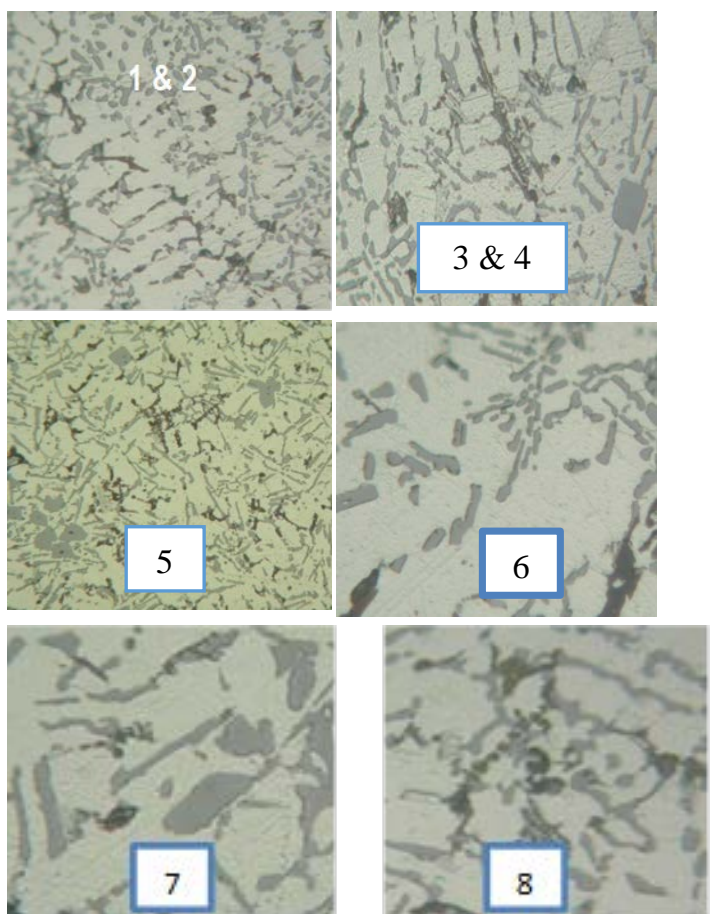

Gambar 13. Hasil uji struktur mikro pada sample A dilokasi 1\&2, 3\&4, 5,6,7 dan 8

\section{Piston B (Imitasi 1)}
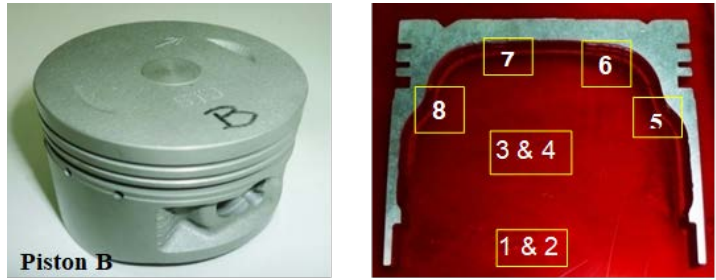

Gambar 14. Sample dan Lokasi pengambilan struktur mikro sampel B (Imitasi 1).
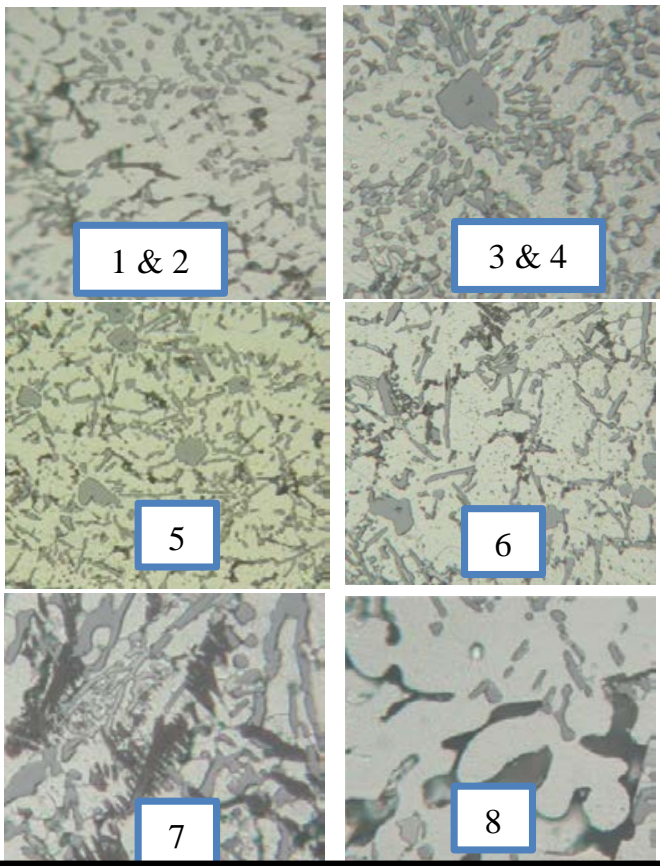
Gambar 14. Hasil uji struktur mikro pada sample B (imitasi 1) dilokasi 1\&2, 3\&4, 5,6,7 dan 8

\section{Piston C (Imitasi 2)}
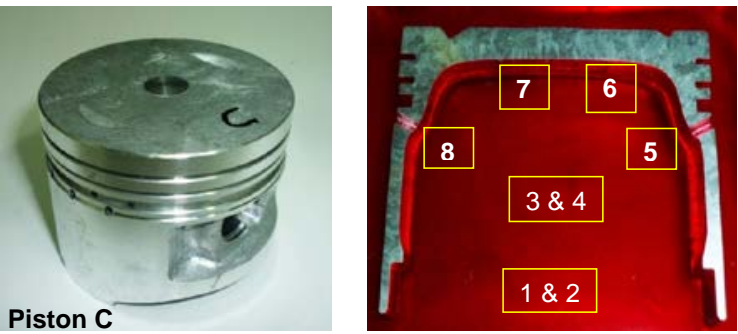

Gambar 15. Sample dan Lokasi pengambilan struktur mikro sampel C (Imitasi 2)
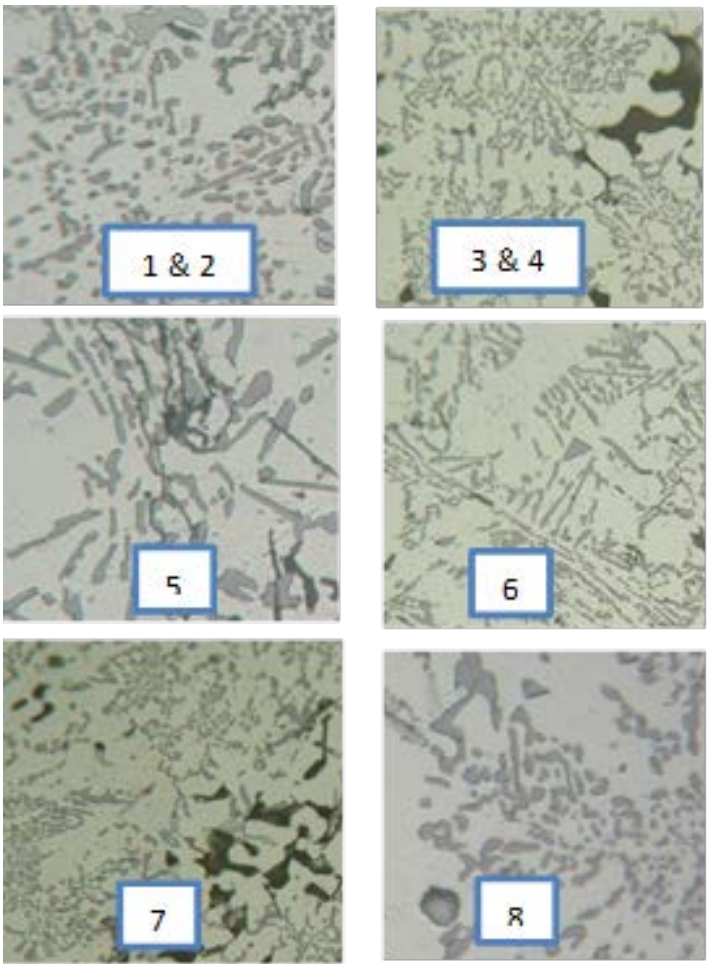

Gambar 16. Hasil uji struktur mikro pada sample C (imitasi 2) dilokasi 1\&2, 3\&4, 5,6,7 dan 8

\section{Uji Kekerasan}

Pengujian kekerasan bertujuan untuk mengetahui kekerasan benda uji terhadap penetrasi suatu material yang lebih keras dengan bentuk dan di bawah pengaruh gaya tertentu sehingga akan didapatkan harga kekerasan dari benda uji. Sebelum dilakukan pengujian kekerasan, penampang yang diuji harus rata dan halus yang bertujuan untuk memudahkan didalam pengukuran ini akan penetrator. Pengujian kekerasan dengan metode Vickers bertujuan menentukan kekerasan suatu material dalam yaitu daya tahan material terhadap indentor intan yang cukup kecil dan mempunyai bentuk geometri berbentuk piramid.

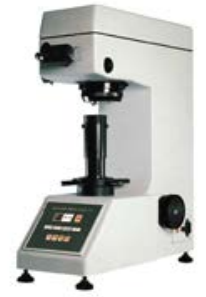

Gambar 17. Alat uji kekerasan Vickers

Kelebihan dari pengujian Vickers ini bisa mengatur kekerasan secara mikro dimana struktur kristal dapat diketahui kekerasannya, dengan demikian pengujian secara Vickers bisa mendapatkan kekerasan mikro dan makro.

Persiapan benda uji

Adapun persiapan benda uji yang dilakukan sebagai berikut :

a) Penghalusan permukaan benda uji

Spesimen uji kekerasan permukaannya harus halus. Alat yang digunakan dalam proses penghalusan adalah amplas dengan nomor 400, 600, 800 dan 1000 secara berurutan.

b) Pemolesan benda uji

Pemolesan spesimen dilakukan dengan menggunakan autosol dan kain halus untuk menghilangkan sisa-sisa goresan dan debu dari hasil pengamplasan agar di dapat permukaan yang lebih halus.

1. Prosedur pengujian

Setelah spesimen dan alat uji telah siap, kemudian di lakukan pengujian dengan langkah-langkah sebagai berikut:

a) Pilih beban yang sesuai dengan jenis identor, beban yang dipakai $3 \mathrm{kgf}$.

b) Pilih dudukan benda uji (anvil) yang sesuai dengan benda ujinya.

c) Letakan benda uji pada anvil, naikan benda uji dengan cara memutar pengikat roda kapstan sampai benda uji menyentuh sudut identor.

d) Setelah melakukan pengujian dengan waktu uji 15 detik, bacalah nilai kekerasan pada alat uji.

Hasil pengujian kekerasan

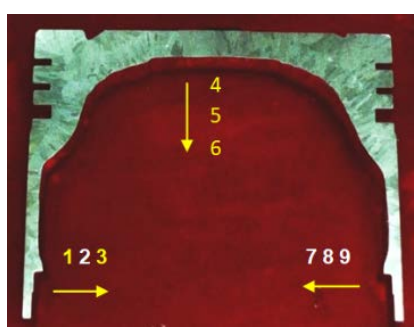

Gambar 18. Lokasi pengambilan uji kekerasan 
Tabel 3. Hasil Uji Kekerasan Piston

\begin{tabular}{|c|c|c|c|}
\hline \multirow{2}{*}{ NO. } & \multicolumn{3}{|c|}{ NILAI KEKERASAN HV } \\
\cline { 2 - 4 } & Piston A & Piston B & Piston C \\
\hline 1 & 128 & 153 & 139 \\
\hline 2 & 127 & 154 & 138 \\
\hline 3 & 124 & 148 & 130 \\
\hline 4 & 130 & 143 & 134 \\
\hline 5 & 134 & 142 & 135 \\
\hline 6 & 130 & 145 & 135 \\
\hline 7 & 131 & 143 & 131 \\
\hline 8 & 130 & 152 & 136 \\
\hline 9 & 127 & 154 & 139 \\
\hline Rata-rata & 129 & 148,2 & 135,2 \\
\hline
\end{tabular}

Data alat uji kekerasan Vickers :

Nama alat : Frank Finotest

Metode Uji : Hardness Vickers (HV)

Beban (P) : $3 \mathrm{Kgf}$

Sudut Identor : $136^{\circ}$

Waktu Uji : 15 detik

Temperatur Uji : $28^{\circ} \mathrm{C}$

Standar Uji ： SNI 19-0409-1989

\section{ANALISIS}

\section{Analisis Uji Komposisi Kimia Piston Merk A,B dan C.}

Setelah dilakukan uji komposisi kimia pada semua merk piston, diketahui piston tersebut termasuk golongan paduan Al-Si. Seperti kandungan di bawah ini:

1. Pada piston A (original) mempunyai kandungan $81,7 \% \mathrm{Al}$ dan $14,0 \% \mathrm{Si}$.

2. Pada piston B (imitasi 1) mempunyai kandungan $82,2 \%$ Al dan $14,3 \%$ Si.

3. Pada piston $\mathrm{C}$ (imitasi 2) mempunyai kandungan $83,5 \% \mathrm{Al}$ dan $13,2 \% \mathrm{Si}$.

Hal ini terlihat karena mempunyai sifat mekanis yang baik, ini terbukti dari hasil uji sifat mekanisnya. Selain itu, dari hasil uji struktur mikro dimana unsur pemadu utama yaitu silikon tersebar merata pada matriks aluminium dan ada sebagian silikon yang membentuk koloni, serta jarak antar butir yang rapat.

Dari beberapa piston ini , dikarenakan kadar silikon yang cukup tinggi ( di atas 12,2 \% ) maka fasa yang terbentuk ialah fasa hypereutektik.

Dalam paduan Al-Si terdapat 3 (tiga) fasa terjadi:

1. Hipoeutektik => terdapat kandungan silikon $<$ $11,7 \%$.

2. Eutektik $\quad=>$ terdapat kandungan silikon sekitar 11,7 \% s/d 12,2 \%.
3. Hypereutektik $=>$ terdapat kandungan silikon diatas $12,2 \%$.

\section{Analisa Uji Struktur Mikro Piston Merk A,B, dan}

C.

Hasil dari pengujian struktur mikro beberapa piston ini dapat disimpulkan bahwa pengujian piston ini memiliki struktur yang berbeda, antara lain:

1. Struktur mikro Piston A material Al-Si berupa Aluminium $\alpha$ (putih) dan fasa Si (abu-abu) bentuk dendritik halus, kondisi baik tidak ditemukan adanya cacat porous, retak atau cacat lainnya.

2. Struktur mikro Piston B material Al-Si berupa Aluminium $\alpha$ (putih) dan fasa $\mathrm{Si}$ (abu-abu) bentuk dendritik halus, kondisi baik tidak ditemukan adanya cacat porous, retak atau cacat lainnya.

3. Struktur mikro Piston C (Imitasi) material Al-Si berupa Aluminium $\alpha$ (putih) dan fasa Si (abu-abu) bentuk dendritik halus, ditemukan adanya cacat pengecoran srinkage dan porousity.

\section{Struktur Mikro Piston A (Original)}
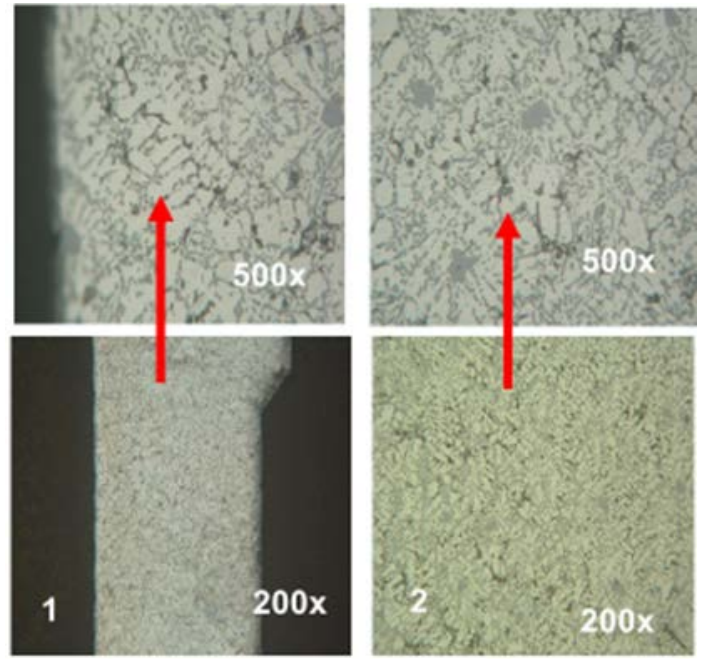

Gambar 19. Struktur mikro lokasi 1 \& 2

Struktur mikro Piston A (lokasi 1 dan 2) material AlSi berupa Aluminium $\alpha$ (putih) dan fasa Si (abu-abu) bentuk dendritik halus, tidak ditemukan adanya cacat porous, retak atau cacat lainnya.

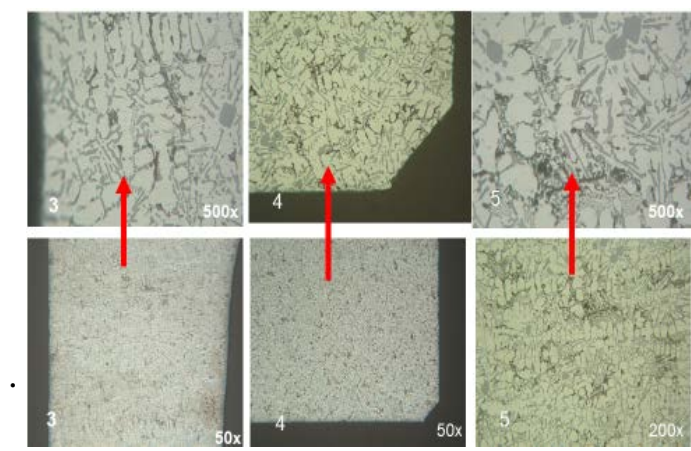

Gambar 20. Struktur mikro lokasi 3,4 dan 5 
Struktur mikro Piston A (lokasi 3, 4 dan 5) material AlSi berupa Aluminium $\alpha$ (putih) dan fasa Si (abuabu) bentuk dendritik halus, tidak ditemukan adanya cacat porous, retak atau cacat lainnya

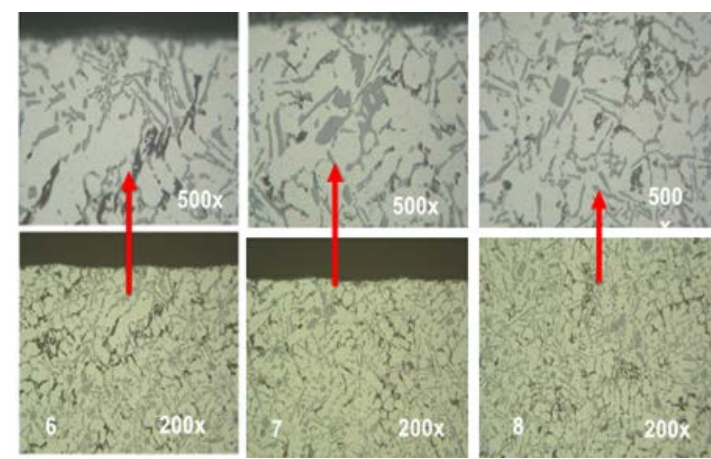

Gambar 21. Struktur mikro lokasi 6,7 dan 8

Struktur mikro Piston A (lokasi 6, 7 dan 8) material AlSi berupa Aluminium $\alpha$ (putih) dan fasa Si (abuabu) bentuk dendritik halus, tidak ditemukan adanya cacat porous, retak atau cacat lainnya.

\section{Struktur Mikro Piston B (Imitasi 1)}
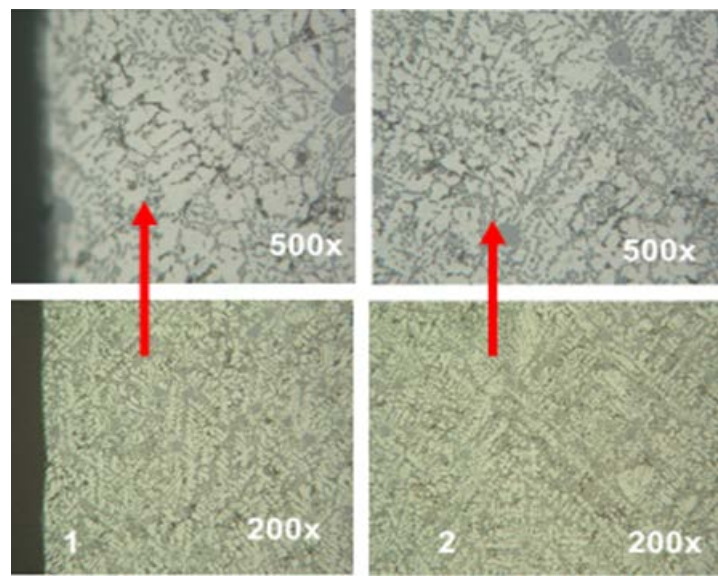

Gambar 22. Struktur mikro lokasi 1 \& 2

Struktur mikro Piston B (lokasi 1 dan 2) material AlSi berupa Aluminium $\alpha$ (putih) dan fasa Si (abu-abu) bentuk dendritik halus, tidak ditemukan adanya cacat porous, retak atau cacat lainnya

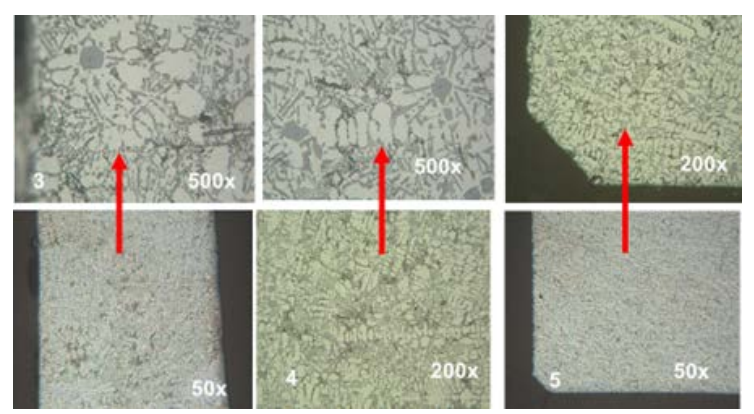

Gambar 23. Struktur mikro lokasi 3,4 dan 5
Struktur mikro Piston B (lokasi 3, 4 dan 5) material AlSi berupa Aluminium $\alpha$ (putih) dan fasa Si (abuabu) bentuk dendritik halus, tidak ditemukan adanya cacat porous, retak atau cacat lainnya.

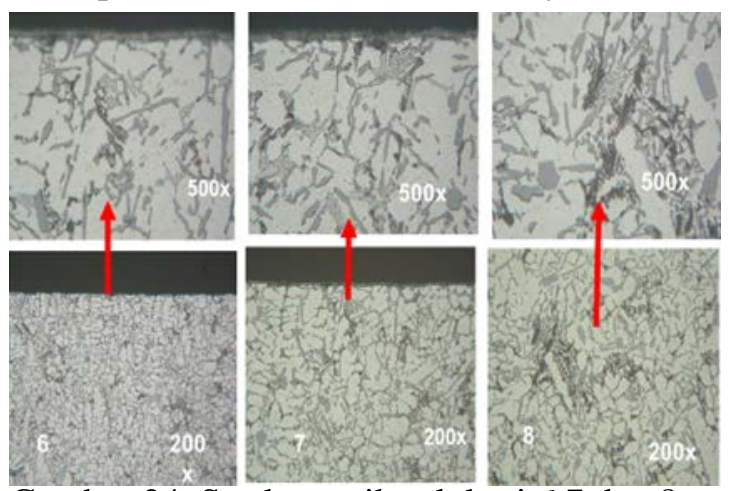

Gambar 24. Struktur mikro lokasi 6,7 dan 8

Struktur mikro Piston B (lokasi 6, 7 dan 8) material AlSi berupa Aluminium $\alpha$ (putih) dan fasa Si (abuabu) bentuk dendritik halus, tidak ditemukan adanya cacat porous, retak atau cacat lainnya

\section{Struktur Mikro Piston C (Imitasi 2)}
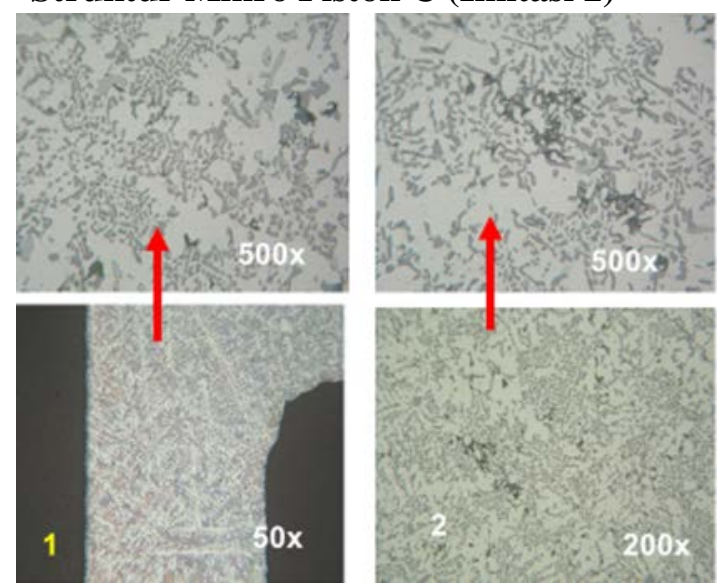

Struktur mikro Piston C (lokasi 1 dan 2) material AlSi berupa Aluminium $\alpha$ (putih) dan fasa Si (abu-abu) bentuk dendritik halus, tidak ditemukan adanya cacat porous, retak atau cacat lainnya.

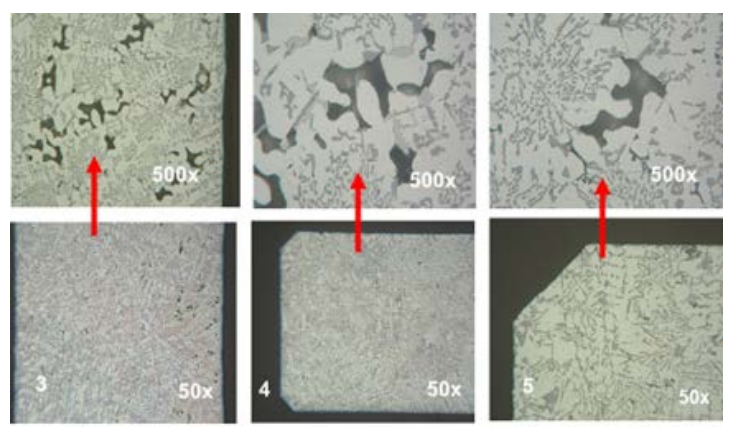

Gambar 26. Struktur mikro lokasi 3,4 dan 5

Struktur mikro Piston C (lokasi 3) terdapat cacat pengecoran berupa porousity sedangkan pada lokasi 4 dan 5 tidak ditemukan adanya cacat. 


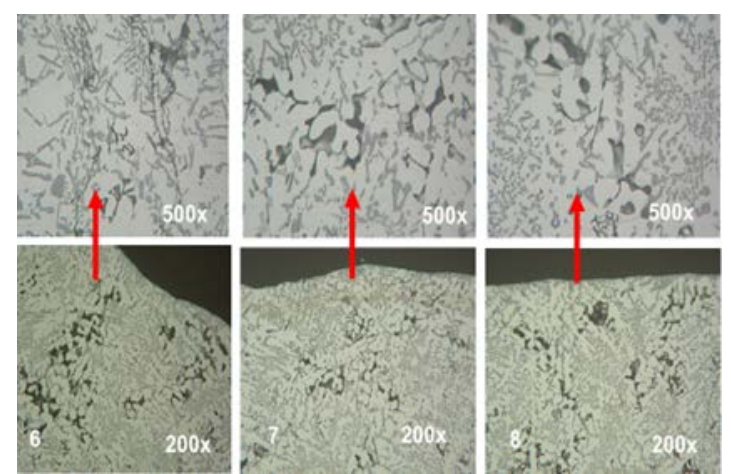

Gambar 27. Struktur mikro lokasi 6,7 dan 8

Struktur mikro Piston C (lokasi 6, 7 dan 8) material AlSi berupa Aluminium $\alpha$ (putih) dan fasa Si (abuabu) bentuk dendritik halus, ditemukan adanya cacat pengecoran berupa porousity.

Analisa Uji Kekerasan Piston Merk A, B dan C.

Setelah dilakukan pengujian kekerasan pada semua merk piston, akan menghasilkan nilai perbandingan harga kekerasan, baik piston original maupun imitasi 1 \& 2 .

Pengujian kekerasan ini menggunakan metode Hardness vickers (HV) dengan indentor intan yang cukup kecil dan mempunyai bentuk geometri berbentuk piramid yang bersudut identornya yaitu $136^{\circ}$, dengan penggunaan beban $\mathrm{P}=3 \mathrm{Kgf}$. Pada suhu temperatur uji antara $28^{\circ} \mathrm{C}$.

Nilai rata-rata pengujian kekerasan bisa dilihat pada grafik dibawah:

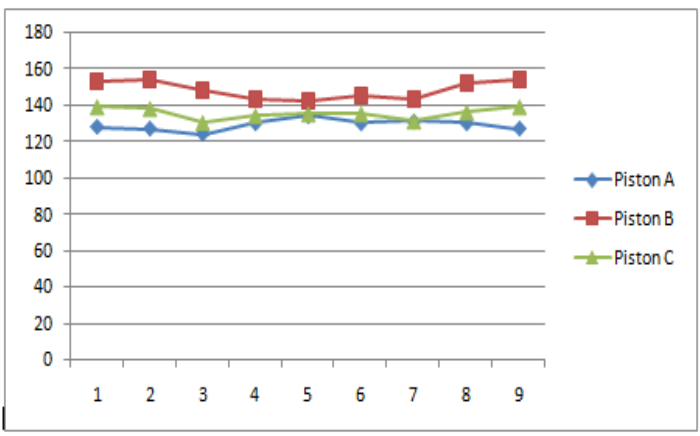

Gambar 28. Grafik Hasil Uji Kekerasan Piston

Terlihat pada gambar nilai kekerasan pada masing-masing piston menunjukan jika nilai kekerasan piston A lebih rendah dibandingkan dengan piston $\mathrm{B}$ dan $\mathrm{C}$, nilai tertinggi kekerasan didapat pada piston $\mathrm{B}$.

Dan nilai kekerasan piston original ini dibawah nilai kekerasan piston imitasi 1 dan 2, terlihat pada grafik nilai piston A kekerasannya lebih sedikit dibandingkan dengan piston B dan C.

Semakin meningkatnya kekerasan piston ini dikarenakan adanya campuran unsur kimia $\mathrm{Cu}$

( Cuprum / Tembaga ). Dengan unsur tembaga pada Aluminium akan meningkatkan kekerasannya karena tembaga bisa memperhalus struktur butir dan akan mempunyai kualitas pengerjaan mesin yang baik, mampu tempa, keuletan yang baik dan mudah dibentuk.

\section{SIMPULAN}

1. Aluminium merupakan logam yang reaktif sehingga mudah teroksidasi dengan oksigen membentuk lapisan aluminium oksida, alumina (Al2O3) dan membuatnya tahan korosi yang baik. Dengan paduan lainnya yaitu Si (silikon) juga mempunyai ketahanan terhadap korosi. Bila bersama aluminium ia akan mempunyai kekuatan yang tinggi setelah perlakuan panas.

2. Bahan paduan yang digunakan pada piston sepeda motor merk A, B dan C ini adalah paduan antara material Al-Si berupa Aluminium $\alpha$ (putih) dan fasa Si (abu-abu).

3. Dari hasil pemeriksaan uji komposisi kimia, Piston A (original) mempunyai kandungan 81,7 \% Al dan 14,0 \% Si. Pada piston B (imitasi 1) mempunyai kandungan 82,2 \% Al dan 14,3 \% Si. Piston C (imitasi 2) mempunyai kandungan $83,5 \% \mathrm{Al}$ dan 13,2 \% Si. Dari hasil pengujian komposisi kimia diketahui ke 3 jenis piston ini masuk kedalam fasa hypereutektik.

4. Struktur mikro Piston A (original) material Al-Si berupa Aluminium $\alpha$ (putih) dan fasa $\mathrm{Si}$ (abu-abu) bentuk dendritik halus, kondisi baik tidak ditemukan adanya cacat porous, retak atau cacat lainnya. Untuk nilai rata-rata kekerasannya yaitu 129 hasil uji hardness vickers (HV).

5. Struktur mikro Piston B (imitasi 1) material Al-Si berupa Aluminium $\alpha$ (putih) dan fasa Si (abu-abu) bentuk dendritik halus, kondisi baik tidak ditemukan adanya cacat porous, retak atau cacat lainnya. Untuk nilai rata-rata kekerasannya yaitu 148,2 hasil uji hardness vickers (HV).

6. Struktur mikro Piston C (Imitasi 2) material Al-Si berupa Aluminium $\alpha$ (putih) dan fasa Si (abu-abu) bentuk dendritik halus, ditemukan adanya cacat pengecoran srinkage dan porousity. Untuk nilai ratarata kekerasannya yaitu 135,2 hasil uji hardness vickers (HV)

7. Dari hasil uji komposisi kimia, nilai kekerasan dan struktur mikro ketiga material tersebut bisa dikatakan mempunyai nilai yang hampir sama

\section{DAFTAR PUSTAKA}

Tata Surdia E. Saito.S, 2000. Pengetahuan Bahan Teknik. Penerbit Pradnya Paramita. Jakarta. 
Van Vlack, H Lawrence. 1995. Ilmu dan Teknologi Bahan, Diterjemahkan oleh Sriati Djaprie, Edisi kelima.

Arismunandar, Wiranto. 2002. Motor Bakar. Edisi kelima. Penerbit ITB Bandung.

http://www.matweb.com/materials for 4000 Series Aluminium Alloy.

http://id.wikipedia.org/wiki/aluminium

http://3bp.blongspot.com/piston

http://www.material_teknik.com 